\title{
Neonatal infection leads to increased susceptibility to $A \beta$ oligomer-induced brain inflammation, synapse loss and cognitive impairment in mice
}

Paula S. Frost ${ }^{1,2}$, Fernanda Barros-Aragão 1,2, Rachel T. da Silva ${ }^{1}$, Aline Venancio ${ }^{3}$, Isadora Matias², Natalia M. Lyra e Silva ${ }^{4}$, Grasielle C. Kincheski ${ }^{4}$, Pedro M. Pimentel-Coelho ${ }^{5}$, Fernanda G. De Felice $\mathbb{C}^{4,6}$, Flávia C. A. Gomes ${ }^{2}$,

Sergio T. Ferreira (iD ${ }^{4,5}$, Claudia P. Figueiredo ${ }^{1}$ and Julia R. Clarke ${ }^{1}$

\begin{abstract}
Harmful environmental stimuli during critical stages of development can profoundly affect behavior and susceptibility to diseases. Alzheimer disease (AD) is the most frequent neurodegenerative disease, and evidence suggest that inflammatory conditions act cumulatively, contributing to disease onset. Here we investigated whether infection early in life can contribute to synapse damage and cognitive impairment induced by amyloid- $\beta$ oligomers (AßOs), neurotoxins found in AD brains. To this end, wild-type mice were subjected to neonatal (post-natal day 4 ) infection by Escherichia coli $\left(1 \times 10^{4} \mathrm{CFU} / \mathrm{g}\right)$, the main cause of infection in low-birth-weight premature infants in the US. E. coli infection caused a transient inflammatory response in the mouse brain starting shortly after infection. Although infected mice performed normally in behavioral tasks in adulthood, they showed increased susceptibility to synapse damage and memory impairment induced by low doses of ABOs (1 pmol; intracerebroventricular) in the novel object recognition paradigm. Using in vitro and in vivo approaches, we show that microglial cells from E. coli-infected mice undergo exacerbated activation when exposed to low doses of AßOs. In addition, treatment of infected pups with minocycline, an antibiotic that inhibits microglial pro-inflammatory polarization, normalized microglial response to $\mathrm{A} \beta \mathrm{O}$ s and restored normal susceptibility of mice to oligomer-induced cognitive impairment. Interestingly, mice infected with by E. coli $\left(1 \times 10^{4} \mathrm{CFU} / \mathrm{g}\right)$ during adolescence (post-natal day 21) or adulthood (post-natal day 60) showed normal cognitive performance even in the presence of AßOs (1 pmol), suggesting that only infections at critical stages of development may lead to increased susceptibility to amyloid- $\beta$-induced toxicity. Altogether, our findings suggest that neonatal infections can modulate microglial response to A $\beta O$ s into adulthood, thus contributing to amyloid- $\beta$-induced synapse damage and cognitive impairment.
\end{abstract}

Correspondence: Claudia P. Figueiredo (claufig@gmail.com) or

Julia R. Clarke (juliaclarke@pharma.ufrj.br)

${ }^{1}$ School of Pharmacy, Federal University of Rio de Janeiro, Rio de Janeiro, RJ 21944-590, Brazil

${ }^{2}$ Institute of Biomedical Sciences, Federal University of Rio de Janeiro, Rio de Janeiro, RJ 21944-590, Brazil

Full list of author information is available at the end of the article.

Edited by D. Bano

\section{Introduction}

Several experiences during the perinatal period, including stress, nutrition, trauma or infections may profoundly and persistently impact the developing brain and the associated behavioral outcomes ${ }^{1-4}$. Epidemiological and experimental data have shown that early exposure to different common pathogens is related to an increased incidence of autism-spectrum disorders ${ }^{5}$ and

\section{(c) The Author(s) 2019}

(c) Open Access This article is licensed under a Creative Commons Attribution 4.0 International License, which permits use, sharing, adaptation, distribution and reproduction cc) in any medium or format, as long as you give appropriate credit to the original author(s) and the source, provide a link to the Creative Commons license, and indicate if changes were made. The images or other third party material in this article are included in the article's Creative Commons license, unless indicated otherwise in a credit line to the material. If material is not included in the article's Creative Commons license and your intended use is not permitted by statutory regulation or exceeds the permitted use, you will need to obtain permission directly from the copyright holder. To view a copy of this license, visit http://creativecommons.org/licenses/by/4.0/. 
schizophrenia ${ }^{6}$. However, to date little is known about the influence of early life infections in the development of inflammatory neurodegenerative diseases in the elderly. In humans, a causal relation between neurodegenerative diseases and neonatal infections has proven difficult to establish due to the long time period between infection and the emergence of clinical symptoms ${ }^{7}$.

Sporadic Alzheimer's disease (AD) is the most common neurodegenerative condition worldwide ${ }^{8}$. Although aging remains the most important risk factor for $\mathrm{AD}$, increasing evidence suggest that cumulative environmental factors and poor lifestyle habits in different life stages contribute to disease development ${ }^{9-12}$. Inflammation is a common denominator to several of these AD risk factors. Besides, it is now known that inflammation plays a central and dual role in Alzheimer's pathology: ${ }^{13}$ while it is initially beneficial for clearance of extracellular aggregates of amyloid- $\beta$ peptide $(A \beta)^{14}$, central toxins that accumulate in $A D$ brains ${ }^{15}$, the sustained pro-inflammatory profile can be extremely deleterious to neuronal function ${ }^{16}$.

Here, we investigate whether an early-life infection increases susceptibility to cognitive impairment induced by low doses of amyloid- $\beta$ oligomers (A $\beta \mathrm{Os})$, neurotoxins found in $A D$ brains during initial stages of the disease ${ }^{17}$. Wild-type mice were subjected to neonatal (post-natal day 4) infection by Escherichia coli, the main cause of infection in low-birth-weight premature infants in the $\mathrm{US}^{18}$. Our results show that early life $E$. coli infection causes an inflammatory response in the mouse brain starting shortly after infection. Although infected mice perform normally in behavioral tasks in adulthood, animals show increased susceptibility to synapse damage and cognitive impairment induced by low doses of $\mathrm{A} \beta \mathrm{Os}$ injected into the lateral ventricle. Using in vitro and in vivo approaches, we show that microglial cells from $E$. coli-infected mice undergo exacerbated activation when exposed to low doses of $A \beta O$ S. In addition, blockage of neonatal infection-induced microglial polarization to a pro-inflammatory profile leads to normalization of behavioral and cellular responses to $\mathrm{A} \beta \mathrm{Os}$ in adult mice. Finally, persistent priming of microglial cells is specifically associated to infections taking place during the neonatal period, since injection of $E$. coli at later stages of development (adolescence and adulthood) did not affect susceptibility of mice to $\mathrm{A} \beta \mathrm{O}$-induced cognitive impairment. Altogether, our findings suggest that neonatal infections can modulate microglial response to $\mathrm{A} \beta \mathrm{O}$ s in adult mice, thus contributing to amyloid- $\beta$-induced synapse damage and cognitive impairment.

\section{Results}

In order to investigate whether an early life inflammatory event modulates the susceptibility of the brain to $\mathrm{A} \beta \mathrm{O}$-induced toxicity, we developed a mouse model of early-life $E$. coli infection. Initially, we determined the amount of $E$. coli that induced no long-term memory deficits or mortality in Swiss mice. Therefore, male pups injected with $0.5 ; 1$ or $2 \times 10^{4} \mathrm{CFU} / \mathrm{g}$ of $E$. coli s.c. at postnatal day $4(\mathrm{P} 4)$ were tested in the novel object recognition task (NOR) at 90 days of age (Fig. 1a). As expected, animals that received a s.c. injection of sterile PBS (sPBS) spent significantly more time exploring the non-familiar than the familiar object used in test session, indicating that they successfully learned the task (Fig. 1b). Conversely, male mice that received $2 \times 10^{4} \mathrm{CFU} / \mathrm{g}$ of $E$. coli at $\mathrm{P} 4$ did not differentiate between familiar and novel objects presented in the test session (Fig. 1b, E. coli 2), indicating that this amount of bacteria induces persistent cognitive impairment per se in mice. Since lower amounts of $E$. coli ( 0.5 or $1 \times 10^{4} \mathrm{CFU} / \mathrm{g}$ ) had no persistent effect on cognition of adult mice (Fig. 1b; E. coli 0.5 ; E. coli 1 ), we chose the intermediate dose of $E$. coli $\left(1 \times 10^{4} \mathrm{CFU} / \mathrm{g}\right)$ for subsequent experiments. Curiously, female pups that received this amount of $E$. coli showed persistent cognitive impairment in the NOR task (Suppl. Fig. 1A-C) suggesting that early life infection may have sex-specific effects on the mouse developing brain.

We previously described that a single intracerebroventricular (i.c.v.) injection of $10 \mathrm{pmol}$ of $\mathrm{A} \beta \mathrm{Os}$ in mice results in impaired formation of NOR memory, whereas 1 pmol of $\mathrm{A} \beta \mathrm{O}$ s i.c.v. have no effect on cognitive function $^{19}$. Based on these previous findings, mice injected at P4 with E. coli $1 \times 10^{4} \mathrm{CFU} / \mathrm{g}$ or sPBS received an i.c.v. injection of either 1 or $10 \mathrm{pmol}$ of $\mathrm{A} \beta \mathrm{O}$ s and were trained in the NOR task, at 90 days of age (Fig. 1c). In agreement to our previous studies ${ }^{19,20}$, control mice that received an i.c.v. injection of $10 \mathrm{pmol} A \beta O s$ showed cognitive dysfunction (Fig. 1d). Interestingly, while 1 pmol of $A \beta O$ s had no effect on cognitive performance of sPBS-treated mice, $E$. coli infected-mice infused with a single subtoxic dose of A $\beta O s$ ( $1 \mathrm{pmol} / \mathrm{site}$, i.c.v.) failed to differentiate between familiar and non-familiar objects, indicating an impaired NOR memory formation (Fig. 1d). The effects appear to be specific on memory formation, since no changes in locomotion (Suppl. Fig. 1D) or exploratory behavior (Suppl. Fig. 1E) were observed.

Synapse loss is a hallmark of $\mathrm{AD}$ and contributes to memory impairment in several conditions ${ }^{21}$. In order to investigate whether adult mice neonatally infected with $E$. coli are more susceptible to A $\beta \mathrm{O}$-induced synapse loss, we quantified hippocampal levels of the pre-synaptic protein synaptophysin $24 \mathrm{~h}$ after i.c.v. injection of oligomers. We found that mice subjected to neonatal $E$. coli infection showed a marked decrease in hippocampal synaptophysin immunolabeling when treated with 1 pmol $\mathrm{A} \beta \mathrm{O}$ i.c.v., when assessed both $24 \mathrm{~h}$ (Fig. 1e) and 7 days after i.c.v. infusion of oligomers (Suppl. Fig. 2A-D), whereas in noninfected mice this subtoxic dose of amyloid- $\beta$ had no 
A

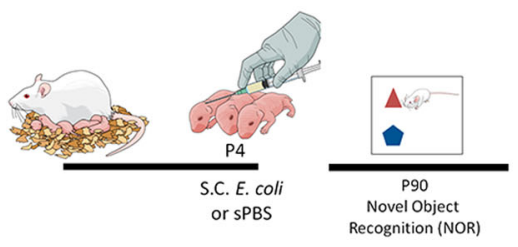

C

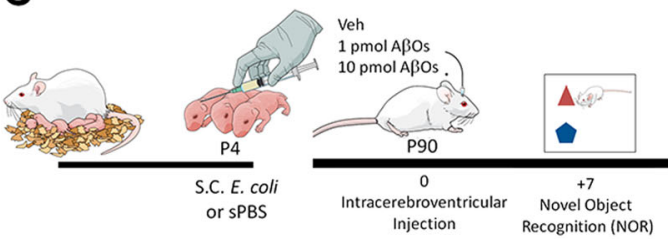

B

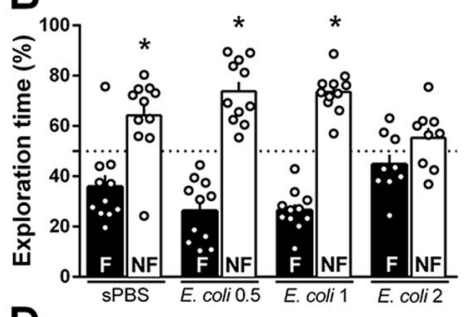

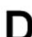

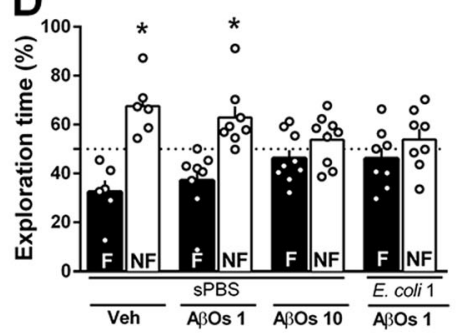

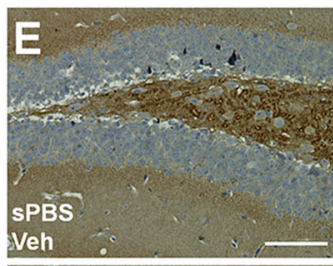
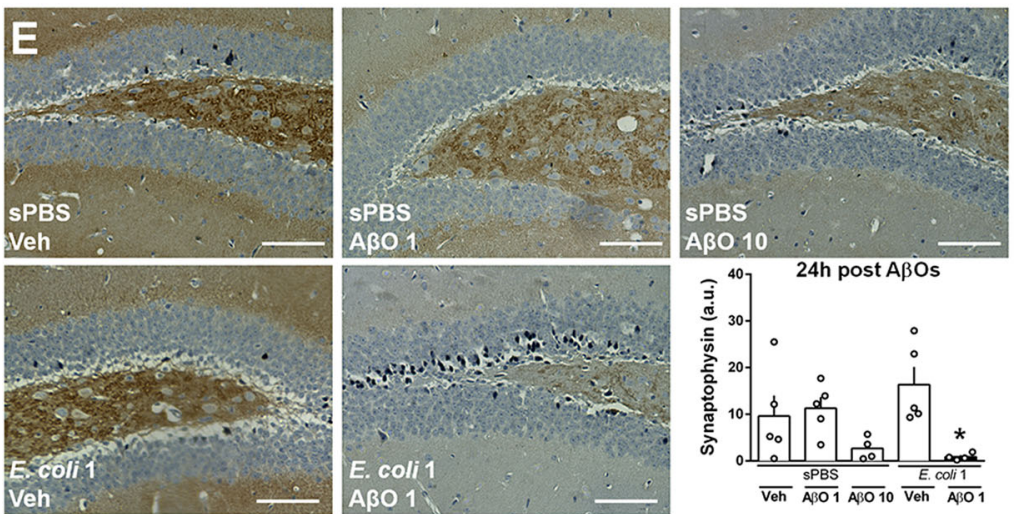

Fig. 1 Neonatal E. coli infection increases susceptibility to ABO-induced cognitive impairment and synapse loss. a Swiss pups received a subcutaneous (s.c.) injection of sterile PBS (sPBS) or $0.5,1$ or $2 \times 10^{4} \mathrm{CFU} / \mathrm{g}$ of body weight of Escherichia coli (E. coli 0.5 , E. coli 1, E. coli 2 , respectively) at post-natal day 4 (P4). At post-natal day 90 (P90), they were tested in the Novel Object Recognition (NOR) task (b). c Mice subjected to s.c. injection of $1 \times 10^{4} \mathrm{CFU} / \mathrm{g}$ of E. coli or SPBS at P4, received an i.c.v. injection of vehicle (Veh), 1 pmol (AßOs 1) or 10 pmol of ABOs (AßOs 10) at P90, and were tested in NOR task (d) seven days later. Bars represent mean \pm S.E.M. of percentage of time spent exploring the familiar (f; black bars) and non-familiar (NF; white bars) objects used in test session. e Representative images of synaptophysin immunoreactivity in the DG hippocampal region of mice subjected to E. coli 1 infection or SPBS at P4, and given an i.c.v. injection of vehicle, AßOs 1 or A 30 s 10. Graph shows integrated immunoreactivity (optical density) for synaptophysin in the hippocampus. Scale bar: $50 \mu \mathrm{m}$. In $\mathbf{b}$ : ${ }^{*} p=0.0125$ for sPBS and ${ }^{*} p<0.0001$ for E. coli 0.5 and $E$. coli 1 ; in (d): ${ }^{*} p=0.0133$ for $\mathrm{sPBS}+$ Veh and ${ }^{*} p=0.0258$ for sPBS + AßOs 1, one-sample Student's $t$ test compared to fixed value $50 . \operatorname{In}(\mathbf{e}):{ }^{*} p=0.0396$ Student's $t$ test compared to $\mathrm{SPBS}+\mathrm{A} \beta \mathrm{Os} 1$

effect on this synaptic protein. Altogether, these findings suggest that previous $E$. coli infection increases susceptibility to $\mathrm{A} \beta \mathrm{O}$-induced synapse damage and memory impairment.

Extensive evidence has shown that decreased maternal care during the neonatal period has persistent effects on adult behavior ${ }^{22,23}$. Therefore, we investigated whether $E$. coli infection at $\mathrm{P} 4$ induced changes in maternal behavior, which could explain changes in adult behavior following $\mathrm{A} \beta \mathrm{O}$ injection. Litters injected with sPBS or E. coli 1 and their respective dams were daily observed to assess maternal behavior. No changes in the percentage of time spent by dams licking (Suppl. Fig. 3A) or feeding pups (Suppl. Fig. 3B) as well as the percentage of time spent at the nest (Suppl. Fig. 3C) were seen between groups. Moreover, no mortality (data not shown) or body weight loss (Suppl. Fig. 3D) were induced by this amount of $E$. coli compared to sPBS-treated mice. We then investigated whether s.c. injection of $E$. coli was associated to systemic infection in neonatal animals. Significant bacteremia were seen both 1 and $24 \mathrm{~h}$ after infection (Suppl. Fig. 4A, B).

Next, we investigated the effects of $E$. coli infection on the developing brain, in order to identify factors that could contribute to the increased susceptibility to A $\beta O$ induced toxicity seen in adulthood. To determine whether E. coli reaches the developing brain after s.c. injection, we performed qPCR in brain samples of mice after infection (Fig. 2a, b) for determination of gamma-proteobacteria 

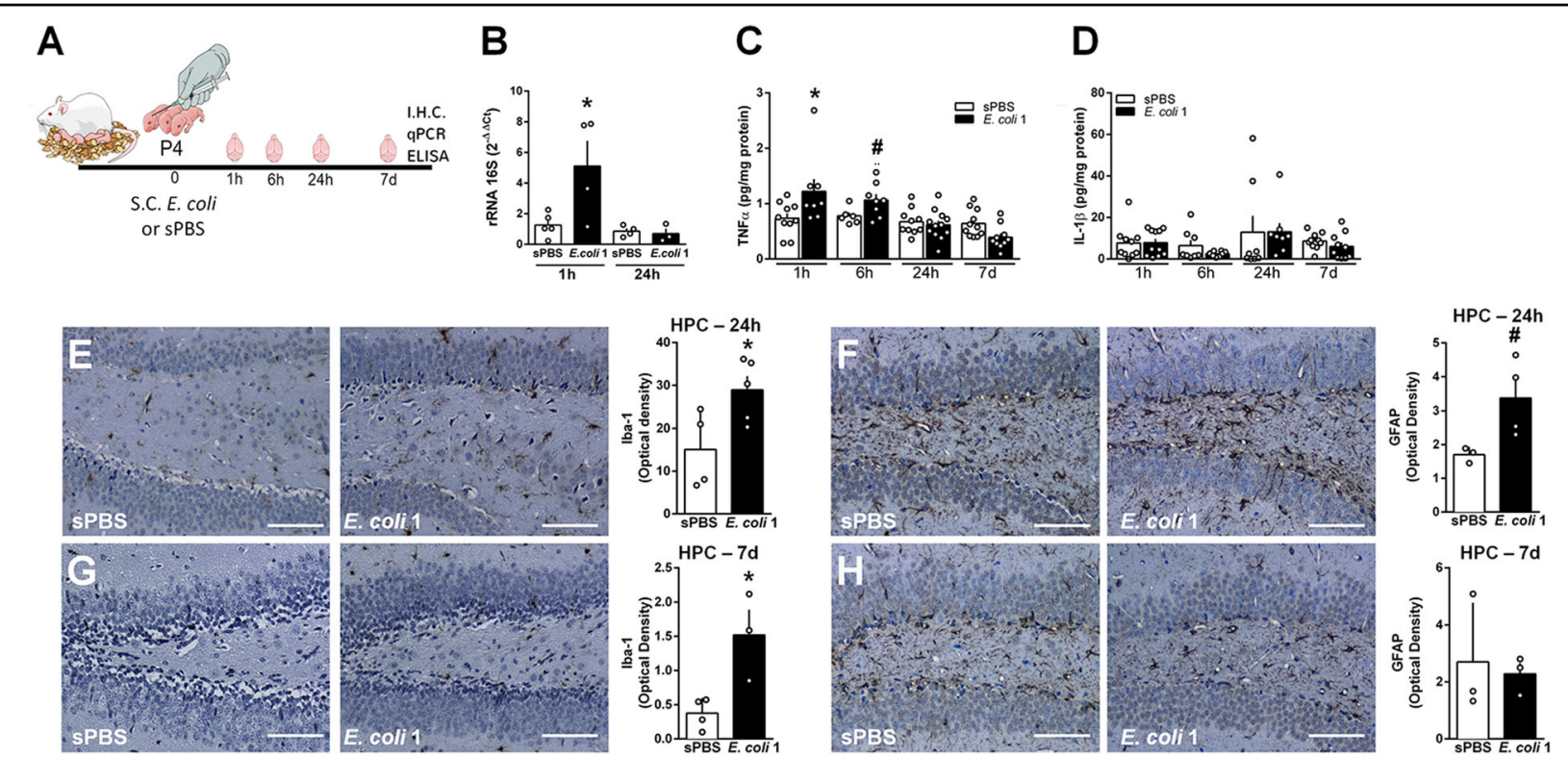

Fig. 2 Neonatal E. coli infection induces transient hippocampal inflammation and astro- and microgliosis. a Swiss pups received a S.C. injection of sterile PBS (sPBS) or E. coli $1 \times 10^{4} \mathrm{CFU} / \mathrm{g}$ (E. coli 1) at post-natal day 4 (P4), and brains were collected 1, 6, $24 \mathrm{~h}$ or 7 days later. b qPCR for gamma-proteobacteria rRNA $16 \mathrm{~S}$ was performed in whole brains of mice 1 or $24 \mathrm{~h}$ after s.c. injection of $E$. coli or sPBS, and normalized by actin. TNF-a (c) and IL-1 $\beta$ levels (d) were measured in brains of mice at different timepoints after s.c. injection of $E$. coli or sPBS. e, $\mathbf{g}$ Representative images of Iba-1 immunoreactivity in the DG hippocampal region of mice $24 \mathrm{~h}(\mathbf{e})$ and 7 days $(\mathbf{g})$ after s.c. injection of E. coli 1 or sPBS. Graphs show integrated immunoreactivity (optical density) for Iba-1 in the hippocampus. $\mathbf{f}$, $\mathbf{h}$ Representative images of GFAP immunoreactivity in the hippocampus of mice $24 \mathrm{~h}$ (f) and 7 days (h) after s.c. injection of E. coli 1 or sPBS. Graphs show integrated immunoreactivity (optical density) for GFAP in the hippocampus. Scale bars $=50 \mu \mathrm{m}$. In (b): ${ }^{*} p=0.037$, in (c): ${ }^{*} p=0.0449,{ }^{\#} 0.0576$, in (e): ${ }^{*} p=0.037$, in (f): ${ }^{*} p=0.0575$, in $(\mathbf{g}):{ }^{*} p=0.0189$, Student's $t$ test

$16 \mathrm{~S}$ ribosomal RNA (rRNA 16 S). High levels of bacterial RNA were found in brains of mice $1 \mathrm{~h}$, but not $24 \mathrm{~h}$, after infection at P4 (Fig. 2b). We hypothesized that the bacterial RNA detected in brain samples $1 \mathrm{~h}$ after infection corresponded to circulating E. coli. To address this issue, $E$. coli-infected neonatal mice were perfused with sterile saline before brain samples were collected and probed for rRNA $16 \mathrm{~S}$ by qPCR. Results were similar to those seen in non-perfused mice: increased levels of E. coli rRNA $16 \mathrm{~S}$ were found in brains of animals $1 \mathrm{~h}$ after infection (Suppl. Fig. 4C). We next investigated whether infection was leading to an increased permeability of the blood brain barrier, by measuring the presence of endogenous IgG in the brain parenchyma following $E$. coli infection ${ }^{24}$. No significant IgG staining was found $1 \mathrm{~h}$ after injection of $E$. coli when compared to brains of sPBS mice, whereas diffuse IgG staining was observed in only 1 brain out of three pups $24 \mathrm{~h}$ after infection (Suppl. Fig. 4D-H). Altogether, these findings suggest that s.c.-injected $E$. coli either enters the brain parenchyma without breaking the integrity of the blood brain barrier, or it binds to the epithelial lining of the choroid plexus and brain ventricles.

To further characterize the effects of neonatal $E$. coli infection, we evaluated the levels of pro-inflammatory cytokines in pups' brain samples at different time intervals after neonatal sPBS or E. coli s.c. injections (Fig. 2a). In agreement, we further found that $E$. coli infection induced a transient increase (after 1 and $6 \mathrm{~h}$ ) in brain levels of the pro-inflammatory cytokine tumor necrosis factor $\alpha$ (TNF$\alpha)$ (Fig. 2c), whereas levels of interleukin $1 \beta$ (IL-1 $\beta$ ) were comparable between groups at the evaluated timepoints (Fig. 2d). We further found an increase in the immunoreactivity for the microglial marker Iba-1 (Fig. 2e) and a trend in increase of GFAP immunoreactivity (an astrocytic marker) (Fig. 2f) in the hippocampi of infected pups $24 \mathrm{~h}$ after bacterial infection when compared to sPBSinjected mice. In addition, while Iba-1 immunoreactivity remained higher in E. coli-infected pups after 7 days of infection (Fig. 2g), levels of GFAP (Fig. 2h) in infected pups were similar to control levels at this later timepoint, thus indicating that hippocampal astrocytes undergo a transient activation following $E$. coli infection.

Since neonatal $E$. coli infection resulted in an increased susceptibility to $\mathrm{A} \beta \mathrm{O}$-induced cognitive impairment in adulthood, we next asked whether this effect is restricted to infection at certain stages of neurodevelopment. To address this issue, we infected adolescent (P21) and adult mice (P60) with E. coli (s.c.; $1 \times 10^{4} \mathrm{CFU} / \mathrm{g}$ ), and at 90 days of age they received an i.c.v. injection of $\mathrm{A} \beta \mathrm{O}$ s or vehicle (Fig. 3a). Interestingly, 1 pmol $A \beta O s$ had no effect on NOR memory formation of animals infected with $E$. coli during these later stages of development (Figs. 3b, c; 


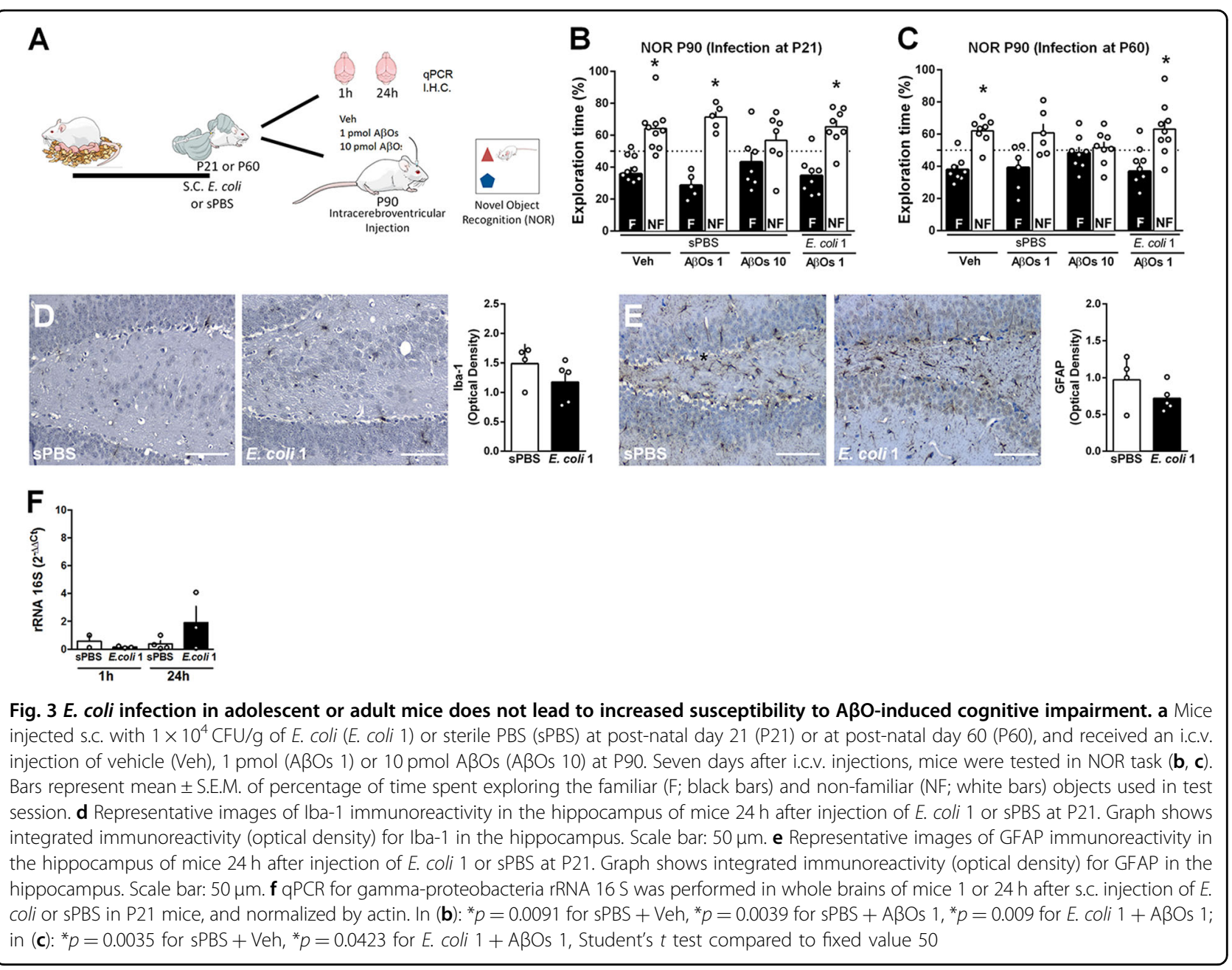

Suppl. Fig. 5A-D). Furthermore, E. coli infection at P21 had no effect on either Iba-1 (Fig. 3d) or GFAP (Fig. 3e) immunolabeling in the hippocampi of infected mice compared to control. To determine whether s.c.-injected $E$. coli reached the brain of adolescent mice, we performed qPCR for gamma proteobacteria rRNA $16 \mathrm{~S}$ subunit in brains of mice infected at post-natal day 21 . In contrast to the brains of neonatal mice, no bacterial RNA was found either 1 or $24 \mathrm{~h}$ after s.c. infection in adolescent mice (Fig. 3f). These findings highlight that infections during the neonatal period have larger potential to cause long-lasting impact on brain and behavior.

Microglial priming is a phenomenon that involves an exaggerated or heightened microglial response to a second inflammatory stimulus ${ }^{25}$, and which has been linked to neurodevelopmental and neurodegenerative diseases ${ }^{26}$. We then investigated whether microglial priming could contribute to the exacerbated response of neonatallyinfected mice to subtoxic amounts of $\mathrm{A} \beta \mathrm{O}$. Microglia from E. coli-infected pups (E. coli $1 \times 10^{4} \mathrm{UFC} / \mathrm{g}$ at P4) were isolated and maintained in culture (Fig. 4a). We found that microglial cells isolated from sPBS-infected mice at $\mathrm{P} 4$ showed a resting morphology in vitro (Fig. 4b). Treatment of these cultures with a subtoxic dose of $A \beta O$ s $(30 \mathrm{nM})$ did not induce either a significant alteration in cell morphology (Fig. 4b) or increased immunoreactivity of the microglia/macrophage marker F4/80 (Fig. 4b, d). Interestingly, microglial cells isolated from brains of $E$. coli-infected mice showed an increase in F4/80 immunoreactivity after exposure to $30 \mathrm{nM}$ of $\mathrm{A} \beta \mathrm{Os}$ (Fig. 4c, d). We next investigated whether microglial priming was also induced by neonatal infection in vivo, by performing a comparative investigation of microglial morphology in different hippocampal subregions of adult mice after i.c.v. injection of vehicle or of the subtoxic dose of $A \beta O$ s $(1 \mathrm{pmol})$. Among mice neonatally treated with sPBS, 1 pmol A $\mathrm{BOs}$ had no effect on the percentage of amoeboid and ramified microglial cells compared to Vehicleinjected mice (Figs. 4e-k, Suppl. Fig. 6). In contrast, the same dose of $\mathrm{A} \beta \mathrm{Os}$ shifted microglial morphology into a predominantly amoeboid state in all hippocampal regions of $E$. coli infected mice (Figs. 4e-k, Suppl. Fig. 6). We also 


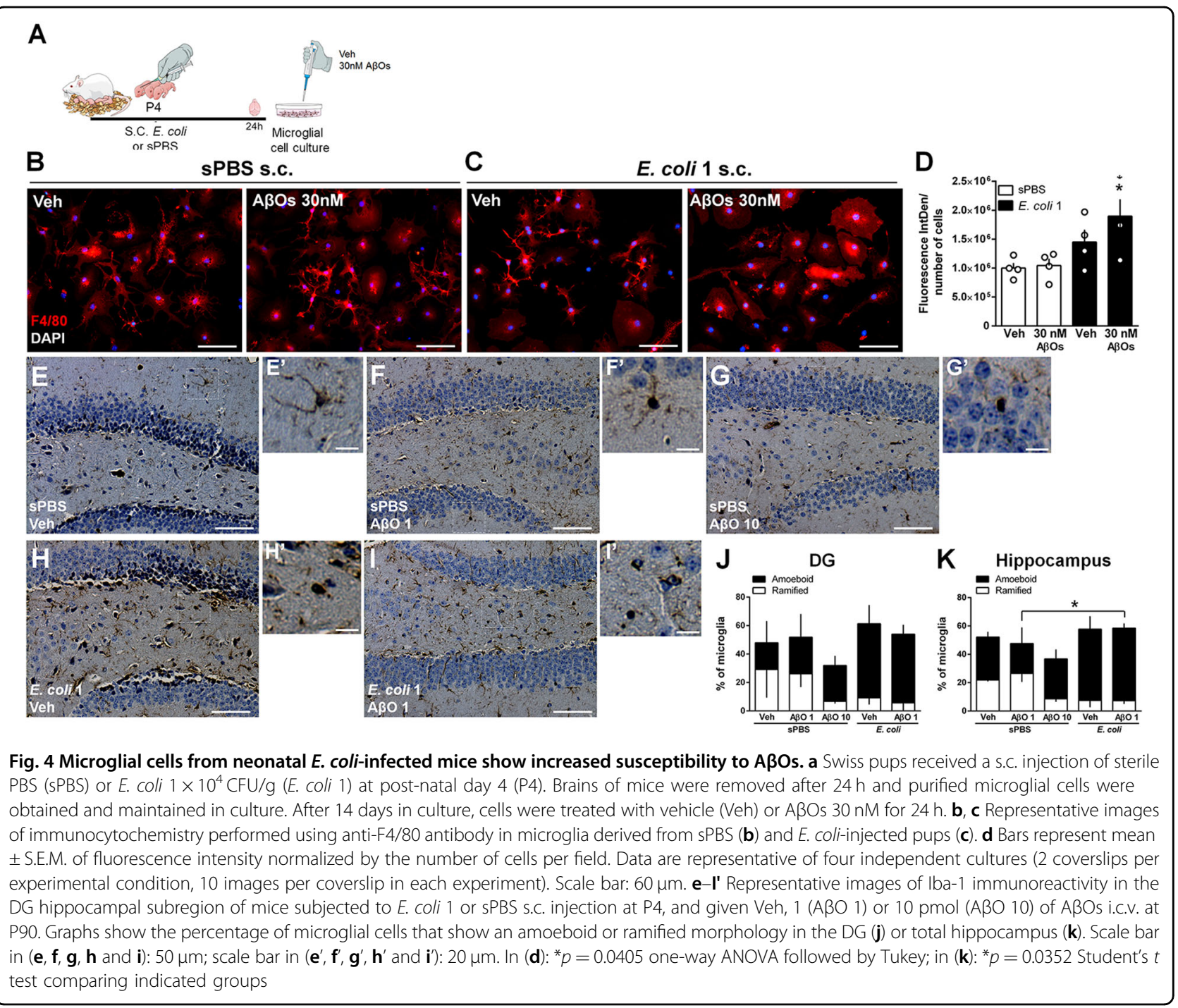

found that brains of infected mice showed predominance of amoeboid microglial cells even in the absence of $\mathrm{A} \beta \mathrm{Os}$ (E. coli-vehicle injected mice), suggesting that infection per se induces persistent microglial morphological changes in vivo (Figs. 4e-k, Suppl. Fig. 6).

We hypothesized that the transient neonatal brain inflammation after $E$. coli infection in mice is crucial for microglial priming and drive the increased susceptibility to memory impairment following exposure to subtoxic doses of $A \beta O s$. To address this hypothesis, polarization of myeloid cells to an M1 profile was blocked with minocycline (22 mg/kg i.p.), administered between P3 and P5 (Fig. 5a). Minocycline had no effect on NOR performance of mice given $\mathrm{A} \beta \mathrm{Os} 1$ or $10 \mathrm{pmol}$ (Fig. 5b, white bars with red borders). Interestingly, neonatal minocycline treatment rescued normal memory performance in mice subjected to $E$. coli infection and exposed to subtoxic doses of A $\beta O s$ (Fig. 5b, black bars with red borders). Next, we evaluated the morphology of microglial cells in minocycline-treated $E$. coli infected mice in response to AßOs. A significant decrease in the percentage of microglial cells with an amoeboid morphology was found in infected mice treated with minocycline compared to infected mice treated with saline, when exposed to subtoxic doses of $A \beta O$ S i.c.v. (Fig. $5 c-h$ ). This effect was more pronounced in the CA1 (Fig. $5 \mathrm{c}-\mathrm{g}$ ) and CA3 hippocampal regions (Suppl. Fig. 7A-E) and even though in the DG results did not reach statistical significance (Suppl. Fig. 7F-J), a protective effect of minocycline was still observed when data from all hippocampal subregions were averaged (Fig. 5h). Altogether, these results strengthen the hypothesis that microglial priming following $E$. coli infection in neonatal mice might account for the increased susceptibility to A $\mathrm{O}$-induced microglial activation, synapse loss and cognitive impairment later in life. 

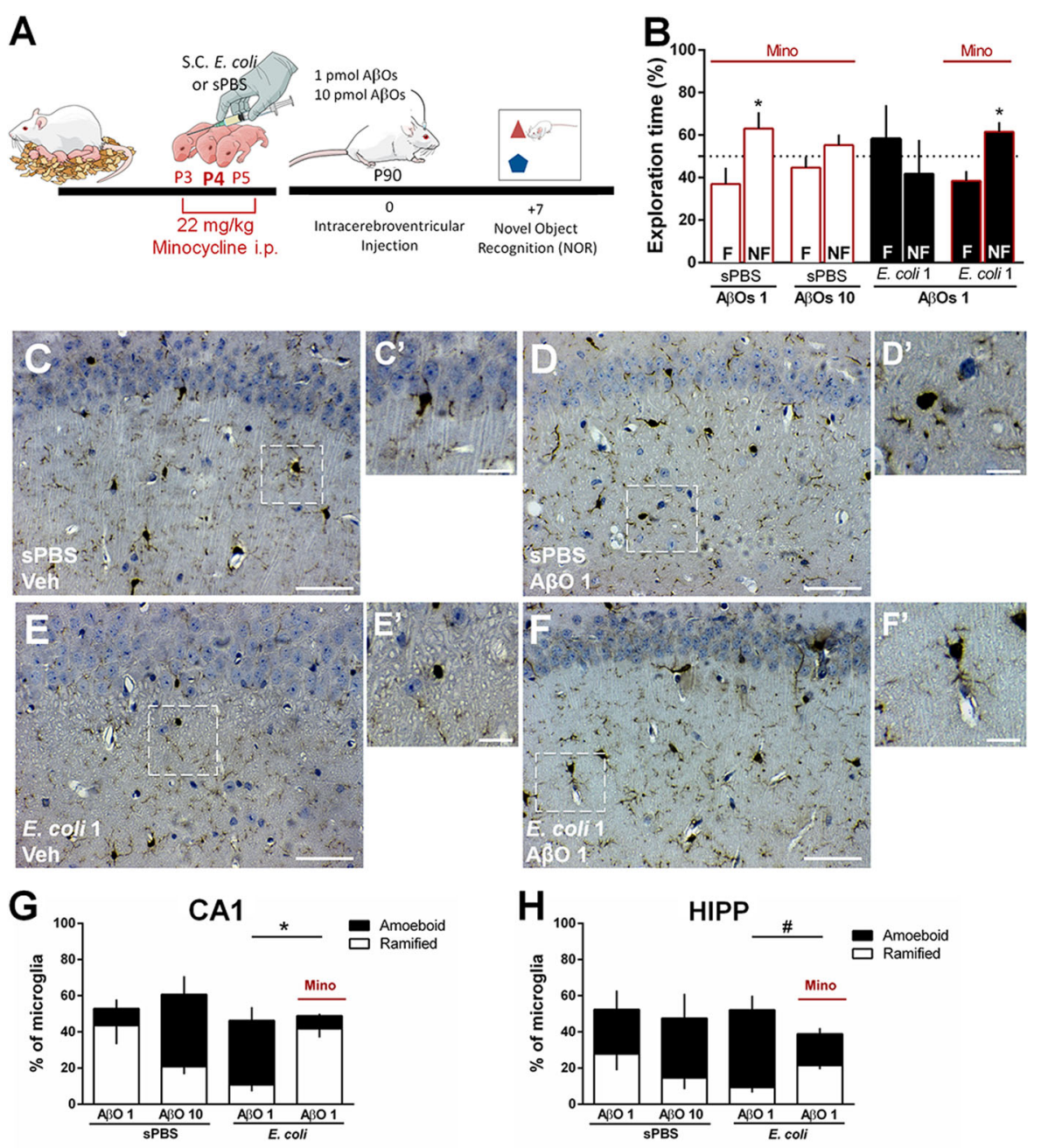

Fig. 5 Early blockage of microglial M1 polarization prevents increased susceptibility to A $\beta O$-induced microglial activation and cognitive impairment. a Neonatal pups received i.p. injection of minocycline $(22 \mathrm{mg} / \mathrm{kg})$ between P3 and P5 and, at P4, they also received a s.c. injection of $1 \times 10^{4} \mathrm{CFU} / \mathrm{g}$ of $E$. coli or sPBS. At P90, mice were treated with an i.c.v. injection of vehicle (Veh), 1 pmol (AßOs 1) or 10 pmol ABOs (AßOs 10). b Seven days after $A \beta O s$ injections animals were tested in NOR task. Bars represent mean \pm S.E.M. of percentage of time spent exploring the familiar (F) and non-familiar (NF) objects used in test session. c-f' Representative images of Iba-1 immunoreactivity in the DG hippocampal subregion of mice subjected to E. coli 1 or sPBS s.c. injection at P4, and given Veh, 1 or 10 pmol of AßOs i.c.v. at P90. Graphs show the percentage of microglial cells that

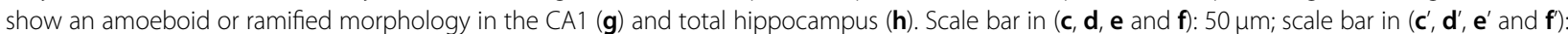
$20 \mu \mathrm{m}$. In (b) ${ }^{*} p=0.0133$ for sPBS + ABOs 1 and ${ }^{*} p=0.009$ for $E$. coli $1+$ AßOs $1+$ Mino, Student's $t$ test compared to fixed value 50 . In (g): ${ }^{*} p=$ 0.0287 and in (h): $\# p=0.0553$

\section{Discussion}

Historically, the brain was regarded as an immunologically privileged $\operatorname{site}^{27}$. However, increasing evidence suggest that several peripheral pro-inflammatory conditions can be signaled through the blood-brain barrier ${ }^{28}$. Studies demonstrate that even mild systemic pathogenic infections can be deleterious to the brain, especially when occurring during vulnerable periods, such as during development $^{3,29}$ or aging $^{30,31}$. Of interest, experiments in animal models showed that neonatal insults, as ischemia, stroke or severe infections, were associated to altered brain response which persist until adulthood ${ }^{32}$. Here, we developed a model of neonatal s.c. $E$. coli infection that causes no mortality, body weight loss or detectable behavioral alterations in adult mice. Viable E. coli particles were found in blood of mice for at least $24 \mathrm{~h}$ after s.c. injection, indicating that this model is associated to systemic infection. Bacterial RNA was found in the brains of infected mice at a very early timepoint post-infection $(1 \mathrm{~h})$ and no consistent increase in blood brain barrier permeability was detected up to $24 \mathrm{~h}$ after infection. Bacteria dynamics in brain samples were reproduced in salineperfused mice, suggesting that $E$. coli detected by qPCR did not correspond exclusively to circulating bacteria. 
Therefore, it is possible that E. coli reached the brain parenchyma without causing BBB disruption (possibly inside immune cells), or injected bacteria remains adhered to the epithelial lining of the choroid plexus and brain ventricles, since intense binding of $E$. coli was shown especially in neonatal rodents ${ }^{33}$. We further found that $E$. coli infection induced a transient shift to a proinflammatory profile in the developing brain. Our results are in agreement with previous studies that reported increased brain levels of pro-inflammatory cytokines within hours ${ }^{34-40}$ after perinatal exposure to gram negative bacteria or LPS. In contrast to the effect of neonatal infections, we found that $E$. coli infection during later stages of development does not lead to hippocampal astrogliosis and microgliosis in mice. Altogether, these results strengthen the idea that there is a critical stage during development when the brain is more sensitive to the effects of pro-inflammatory peripheral stimuli.

The observation that systemic inflammatory diseases can contribute to sporadic $\mathrm{AD}$ onset $^{41}$ has led to the hypothesis that periphery-derived pro-inflammatory molecules could also influence brain response to both physiological and pathological conditions ${ }^{42}$. To date, a few clinical studies have suggested the existence of a relationship between systemic infections and different hallmarks of AD. The incidence of two or more unspecific infections over a period of 4 years was associated with an increased risk of $\mathrm{AD}^{43}$, and a single episode of pneumonia resulted in an accelerated development of dementia in elderly $^{44}$. Other groups have used transgenic mouse models of $\mathrm{AD}$ to investigate whether perinatal infections contribute to $\mathrm{AD}$ progression ${ }^{45}$. It is important to note that these studies were performed in animal models mimicking genetic, familial variants of $\mathrm{AD}$, which are not always good representatives of sporadic AD development in humans ${ }^{46}$. Of note, studies in healthy human subjects and mice have shown that $A \beta$ peptide is constantly generated under physiological conditions in the brain ${ }^{47-49}$. Moreover, since AD pathology is known to start many years before the clinical onset of symptoms, it is important to investigate whether systemic infections contribute to increase the risk of $\mathrm{AD}$ development, or only accelerate ongoing disease. Here, we report that a single exposure to $E$. coli during the neonatal period is sufficient to increase the susceptibility of mice to cognitive impairment and synapse loss after a single i.c.v. infusion of subtoxic doses of $A \beta O s$. Therefore, we speculate that early life infections could increase the risk to develop mild-cognitive impairment and $\mathrm{AD}$, depending on the individual response to physiological generation of $A \beta$ in the patients' brains. This hypothesis should be further confirmed by additional epidemiological and experimental studies. Moreover, the timing of an immunological challenge is very important when considering possible lasting effects. Our results show that mice infected during adolescence or adulthood showed normal cognitive performance when $\mathrm{A} \beta \mathrm{O}$ s are infused into the brain, in contrast to what was found following neonatal infection. Previous studies have found that $E$. coli adheres significantly more to the choroid plexus of neonatal rats compared to that of adult animals, under identical experimental conditions ${ }^{33}$. In agreement with these findings, we found that when adolescent mice are infected s.c. with $E$. coli, bacteria are not detectable in the brain by qPCR either 1 or $24 \mathrm{~h}$ after infection, in contrast to our results following infection in neonatal mice. These findings highlight that infections during the neonatal period have larger potential to cause long-lasting impact on brain and behavior.

Despite the evidence of serious late effects caused by early-life infections on the developing brain, the underlying mechanisms are not well understood. Primed microglial cells are more susceptible to adopt a proinflammatory state when exposed to a second mild inflammatory hit, a phenomenon that was shown to occur in vivo following early-life exposure to LPS or E. coli in rodents ${ }^{25}$. Recent evidence support a central role of microglial cells in performing phagocytosis of dysfunctional synapses ${ }^{50}$, in several conditions including $\mathrm{AD}^{51}$. Here, we showed that microglial cells from $E$. coli-infected pups become over responsive and undergo exaggerated activation when exposed to subtoxic doses of $\mathrm{A} \beta \mathrm{Os}$, in vitro and in vivo, leading to synapse loss and cognitive impairment. Similar results were seen in all hippocampal subregions, suggesting that there is not a subpopulation of microglial cells which is particularly sensitive to the effects of neonatal $E$. coli infection. In addition, we found that by blocking microglial activation shortly after infection with minocycline, we were able to restore normal susceptibility of these cells when animals were exposed to subtoxic doses of $\mathrm{A} \beta \mathrm{O}$ s later in life, and this also led to normalized memory function in the presence of low doses of $\mathrm{A} \beta$ oligomers. These results strengthen the hypothesis that neonatal infection induces microglial priming, and that overactivation of these primed cells in response to low amounts of $\mathrm{A} \beta \mathrm{O}$ s later in life leads to cognitive impairment.

It is known that early-life stressors may have differential impacts on subjects of both sexes ${ }^{52,53}$. One limitation of our study is that we used only male mice in behavioral evaluations. This was due to fact that, under our conditions, female pups were more susceptible to long-term cognitive effects of early-life $E$. coli infection, and further studies should focus on the sex-specific effects of $E$. coli on the developing brain.

Altogether, our findings highlight the need for special attention to the potential late burden of early life bacterial infections. Our data provide mechanistic insight into the long-term consequences of neonatal infections and 
suggest that these conditions might be associated to increased susceptibility to neurodegenerative diseases later in life. Further efforts should be targeted to the discovery of pharmacological approaches that could hamper in vivo infection-induced microglial priming and thus prevent its late deleterious effects to the brain.

\section{Materials \& methods \\ Experimental design}

The aim of this study was to evaluate whether early-life infection can increase susceptibility to cognitive impairment induced by AßOs. All pups in each litter received the same treatment to avoid cross-contamination, and litters were assigned to a single group by simple randomization. Researchers were blind to experimental conditions when conducting the experiments and analyzing the results.

\section{Statistical analyses}

Statistical analysis was performed using GraphPad Prism 6.01 (GraphPad, San Diego, CA). Data are reported as means \pm S.E.M. Gaussian distribution of data was assessed using the D'Agostino-Pearson normality test. For data with Gaussian distribution, the Rout's test was employed to identify potential outliers, which were then excluded from further analyses.

Data from the novel object recognition test were analyzed by one-sample $t$ test compared to the fixed value of 50. For all other data, either unpaired Student's $t$ test or one-way ANOVA followed by Tukey's post hoc test was used. $\mathrm{p}$ values are indicated in the corresponding figure legend.

\section{Animals and mating}

Naïve 10 weeks-old Swiss mice were obtained from our breeding colony and mated for 2 weeks (four females per male). After this period, males were removed and females were kept in individual cages until the birth of the offspring. All procedures followed the Principles of Laboratory Animal Care from the National Institutes of Health and were approved by the Institutional Animal Care and Use Committee of the Federal University of Rio de Janeiro (protocol \#049/14).

\section{Subcutaneous Escherichia coli infection}

Male and female pups received s.c. injection of sterile PBS (sPBS) or different doses of E. coli ATCC 25922 in a total volume of $0.05 \mathrm{~mL}$ at post-natal days 4 (P4), 21 (P21) or 60 (P60). For E. coli injection, all pups were removed from the mother at the same time, placed into a clean cage with bedding, injected individually and returned to the mother as a group. The whole procedure did not take longer than $5 \mathrm{~min}$. All littermates received the same treatment in order to avoid cross-contamination. E. coli injection triggered no mortality, independent of concentration. In an independent experiment, maternal care was evaluated in E. coli and sPBS groups from post-natal day 2 to post-natal day 8 , according to the procedure described by Reis and colleagues (2014). At P21, mice were weaned and placed with same-sex littermates (2-5 mice per cage). Mice were housed in polypropylene cages and maintained at $25^{\circ} \mathrm{C}$ with controlled humidity, under a $12 \mathrm{~h}$ light/dark cycle and ad libitum access to water and chow. To control for litter effects, a maximum of two pups per litter across a minimum of 4 different litters were assigned to a single experimental group.

\section{Preparation of $\mathrm{A} \beta \mathrm{BS}$}

$\mathrm{A} \beta$ oligomers were prepared weekly from synthetic $\mathrm{A} \beta_{1-42}$ (American Peptide, Sunnyvale, CA) as described previously $^{19,54}$. The peptide was dissolved in $1 \mathrm{mM}$ hexafluoroisopropanol (HFIP), which was then evaporated for the formation of a dried film that was stored at $-80^{\circ} \mathrm{C}$. Films were then dissolved in DMSO to a final concentration of $5 \mathrm{mM}$, followed by ice-cold PBS and incubated overnight at $4{ }^{\circ} \mathrm{C}$. After incubation, the preparation was centrifuged $(14,000 \times g, 10 \mathrm{~min})$ and supernatant was collected. Preparations were routinely characterized by HPLC size-exclusion chromatography (SEC) under nondenaturating conditions. Occasionally, preparations were also characterized by western immunoblots using anti-A $\beta$, 6E10 (Abcam, Cambridge, MA, cat\#ab54518) or anti-A $\beta$ oligomer $\mathrm{NU} 4^{55}$, as previously described ${ }^{56-58}$. SEC analysis reveals that $\mathrm{A} \beta \mathrm{O}$ preparations comprise a mixture of high-molecular weight (molecular masses ranging from 80 to $150 \mathrm{kDa}$ ) and low-molecular weight (average molecular mass $\sim 10 \mathrm{kDa}$ ) oligomers ${ }^{19}$. Protein concentration was determined using the BCA kit (Thermo Fisher Scientific, Waltham, MA). Oligomers were kept at $4{ }^{\circ} \mathrm{C}$ and used within $48 \mathrm{~h}$ of preparation.

\section{Evaluation of maternal behavior}

Maternal behavior was evaluated between post-natal days 2 and 8 , according to the procedure described by Reis and colleagues (2014). Briefly, the percentage of time spent by dams licking or feeding pups, and percentage of time they spent at the nest were assessed in four $1 \mathrm{~h}$-long observation sessions performed each day at the following hours of the day: 8:00 AM, 1:00 PM, 4:00 PM and 7:00 PM.

\section{Intracerebroventricular (i.c.v.) injections}

For i.c.v. injections, animals were anesthetized for $7 \mathrm{~min}$ with $2.5 \%$ isoflurane (Cristália, Itapira, Brazil) using a vaporizer system and gently restrained only during the injection procedure itself, as described ${ }^{19,59}$. A $30 \mathrm{G}$ $2.5 \mathrm{~mm}$-long needle was unilaterally inserted $1 \mathrm{~mm}$ to the right of the midline point equidistant from each eye and 
$1 \mathrm{~mm}$ posterior to a line drawn from the anterior base of the eye. $\mathrm{A} \beta \mathrm{Os}(1 \mathrm{or} 10 \mathrm{pmol})$ or vehicle were injected in a final volume of $3 \mu \mathrm{l}$, and the needle was kept in place for $30 \mathrm{~s}$ to avoid backflow. Accurate placement of the needle into the right lateral ventricle was confirmed by macroscopic examination of dissected brains before immunohistochemistry. Mice showing any signs of misplaced injections or brain hemorrhage $(\sim 5 \%$ of animals throughout our study) were excluded from further analysis.

\section{Minocycline treatment}

When indicated, neonatal mice received daily i.p. injections of minocycline (Sigma-Aldrich, St. Louis, MO, cat\# M9511; $22 \mathrm{mg} / \mathrm{kg})^{60,61}$ or saline between post-natal days 3 and 5 .

\section{Novel object recognition test}

The novel object recognition test was performed in an open field arena measuring $30 \times 30 \times 45 \mathrm{~cm}$, where objects were fixed to the box using tape, as described ${ }^{19}$. Preliminary tests showed that none of the objects used in our experiments evoked innate preference. Before training, each animal was submitted to a 5-min-long habituation session, in which they were allowed to freely explore the empty arena. During this habituation session, total distance traveled was measured using Anymaze software (Stoelting Co, Wood Dale, IL), to verify possible effects of treatments on locomotor behavior. Training consisted of a 5 min-long session during which animals were placed at the center of the arena in the presence of two identical objects. Time spent exploring each object was recorded. Sniffing and touching the objects were considered as exploratory behavior. The arena and objects were thoroughly cleaned between trials with $70 \%$ ethanol to eliminate olfactory cues. Two hours after training, animals were again placed in the arena for a 5 min-long test session, and one of the objects used in the training session was replaced by a new one. Again, time spent exploring each object was recorded. Results were expressed as percentage of time exploring each object during the training or test sessions and were analyzed using a one-sample Student's $t$ test comparing the mean exploration time for each object with the fixed value of $50(50 \%$, i.e., no differentiation between objects). By definition, animals that recognize the familiar object as such (i.e., learn the task) explore the novel object $>50 \%$ of the total time.

\section{Immunohistochemistry}

Mice were deeply anaesthetized with $1.5 \mathrm{~mL} / \mathrm{kg}$ of a solution containing $10 \%$ ketamine and $2 \%$ xylazine (intraperitoneally). They were then transcardially perfused with cold phosphate-buffered saline (PBS) solution followed by fresh $4 \%$ formaldehyde. Brains were removed, post-fixed for $24 \mathrm{~h}$ in $4 \%$ formaldehyde and embedded in paraffin after dehydration and diaphanization. Paraffinembedded brain tissue sections $(3-5 \mu \mathrm{m})$ were immersed in xylene for $10 \mathrm{~min}$, rehydrated in absolute ethanol followed by 95 and $70 \%$ solutions of ethanol in water. Another set of samples were cryopreserved after perfusion, and slides with frozen coronal brain sections $(40 \mu \mathrm{m}$ thickness) were fixed in acetone for $30 \mathrm{~min}$. In order to inactivate endogenous peroxidase, paraffin-embedded or frozen slices were incubated with $3 \% \mathrm{H}_{2} \mathrm{O}_{2}$ in methanol. Antigens were reactivated by treatment with $0.01 \mathrm{M}$ citrate buffer for $40 \mathrm{~min}$ at $95^{\circ} \mathrm{C}$. Slides were washed in PBS and incubated with primary antibodies (rabbit antiGFAP antibody, 1:500, Agilent cat\# Z0334, RRID: AB_10013382; rabbit anti-Iba-1 antibody, 1:1000, Wako cat\# 016-20001, RRID:AB_839506; rabbit anti-Ki-67, 1:50, Abcam cat\# ab15580, RRID:AB_443209; mouse antisynaptophysin, 1:500, Sigma-Aldrich cat\# S5768, RRID: AB_477523) for $12-16 \mathrm{~h}$ at $2-8^{\circ} \mathrm{C}$. After washing with PBS, slides were incubated with biotinylated secondary antibodies for $1 \mathrm{~h}$ at room temperature, washed twice with PBS and incubated with streptavidin-biotin-peroxidase (Vector Laboratories, Burlingame, CA) for $30 \mathrm{~min}$. Slides were then covered with 3,3'-diaminobenzidine solution (0.06\% DAB in PBS containing 2\% DMSO and 0.018\% $\mathrm{H}_{2} \mathrm{O}_{2}$ ) for 1 to 5 min or until a brown precipitate could be observed. Identical conditions and reaction times were used for slides from different animals (run in parallel) to allow comparison between immunoreactivity optical densities. Reactions were stopped by immersion of slides in distilled water. Counter-staining was performed with Harris hematoxilin. Slides were imaged using a Sight DS5M-L1 digital camera (Nikon, Melville, NY) connected to an Eclipse 50i light microscope (Nikon) at x200 magnification.

One image from each hippocampal subfield (CA1, hilus, DG or CA3) and in the subventricular zone (SVZ) in each hemisphere were obtained using 200x magnification, and an optical density threshold that best discriminated staining from background was defined using Image $(\mathrm{NIH}$, Bethesda, MD; RRID:SCR_003070), as described ${ }^{62}$. Total pixel intensity was determined for each image and data are expressed as integrated optical density (OD).

For determination of microglial morphology, immunostaining for Iba- 1 was performed as described above, in brains of mice $24 \mathrm{~h}$ after i.c.v. injection of vehicle or $\mathrm{A} \beta \mathrm{O}$ (1 or $10 \mathrm{pmol}$ ). Each subject was evaluated in duplicate and the total number of microglial cells was quantified in the hippocampus (CA1, hilus, DG and CA3), using 2 images per hippocampal subregion. Cells were then further classified as ramified ( $>3$ primary ramifications), amoeboid (no primary processes) or intermediary (1-3 ramifications). 
For endogenous IgG staining, mice were deeply anesthetized and transcardially perfused as described above. Brains were rapidly removed from skulls, postfixed in PFA $4 \%$ for $24 \mathrm{~h}$ and cryoprotected in sucrose $20 \%(\mathrm{w} / \mathrm{v})$. Brains were mounted in OCT, frozen at $-20^{\circ} \mathrm{C}$ and $20 \mu \mathrm{m}$-thick sections were obtained in a cryostate (Leica). Slides containing two to four sections were washed with $0.3 \%$ Triton X-100 in PBS $(3 \times 5 \mathrm{~min})$, followed by an overnight incubation with a biotinylated goat anti-mouse IgG $(\mathrm{H}+\mathrm{L})$ antibody (1:200, Vector Laboratories, cat\# BA-9200, RRID:AB_2336171). Binding was visualized using the peroxidase-based Vectastain $A B C$ kit (Vector Laboratories, cat\# PK-6100, RRID:AB_2336819) and 3,3'diaminobenzidine (Vector Laboratories, cat\# SK-4100, RRID:AB_2336382). Tissues were thereafter washed with PBS $(3 \times 5 \mathrm{~min})$, dehydrated through graded concentrations of alcohol, cleared in xylene and mounted on Entellan (Merck Millipore, cat\# 1079610100). As a positive control of reaction conditions, sections from adult AG129 mice infected with the Zika virus African MR766 strain ${ }^{24}$ were run in parallel.

\section{Bacteremia assessment}

For bacteremia assessment, blood was collected under sterile conditions from anesthetized mice at different times post-infection. Heparin was used to avoid clotting. Blood samples were plated on dishes covered with nonselective Brain Heart Infusion (BHI) $+5 \%$ Agar and incubated at $37^{\circ} \mathrm{C}$ for $24 \mathrm{~h}$. After incubation, number of colony-forming units (CFU) were counted for estimation of the number of CFU per milliliter of blood. Each sample was plated in duplicate.

\section{Microglial cultures}

For microglial cultures, half of the pups in each litter received a s.c. injection of E. coli $\left(1 \times 10^{4} \mathrm{CFU} / \mathrm{g}\right)$ ant the other half received an equal volume of sPBS. Twenty four hours later, pups were killed and their brains were collected. Meningeal layers were carefully removed and the hippocampus and cortices were dissected, homogenized in Dulbecco's Modified Eagle's Medium (DMEM)-F12 medium (Invitrogen, Carlsbad, CA) and centrifuged $\left(1500 \mathrm{rpm}, 2 \mathrm{~min}, 4^{\circ} \mathrm{C}\right)$. Pellets were solubilized in DMEM-F12 medium enriched with $10 \%$ fetal bovine serum, penicillin, streptomycin, and fungizone $(0.65 \mu \mathrm{M}$; all from Sigma Aldrich, St. Louis, MO). Cells were cultured in $75 \mathrm{~cm}^{2}$ cell culture bottles (Corning Glass, Corning, NY) which were pretreated with poly-L lysine overnight (Sigma Aldrich). Cells were maintained at $37^{\circ} \mathrm{C}$ in a humidified chamber with $5 \% \mathrm{CO}_{2}$ for 14 days. Then, the microglial cells were isolated by vigorous shaking for $45-60 \mathrm{~min}$ as previously described ${ }^{40}$, resulting in a purified culture consisting of $95 \%$ of microglial cells. Microglia were then transferred to 24 -well plates $\left(1 \times 10^{5}\right.$ cells/ well) with glass coverslips pretreated with poly-L lysine, and cultured with DMEM-F12 medium supplemented with $10 \%$ fetal bovine serum. Twenty-four hours later, cells were treated with subtoxic amounts of $A \beta O s$ $(30 \mathrm{nM})$, determined based on previous work from our group $^{63}$, or an equivalent volume of vehicle.

\section{Immunocytochemistry}

For immunocytochemistry, culture medium was removed and cells were fixed (paraformaldehyde $4 \%$ for $15 \mathrm{~min}$ ), blocked (PBS, Triton $0.2 \%, 10 \%$ bovine serum for $1 \mathrm{~h})$ and incubated overnight with anti-F4/80 (1:200, Abcam cat\# ab6640, RRID:AB_1140040) at $4{ }^{\circ} \mathrm{C}$. Secondary antibody (anti-rabbit Alexa 488, 1:1 000, Thermo Fisher Scientific cat\# A32723, RRID:AB_263375) was incubated for $2 \mathrm{~h}$, at room temperature. Nuclei were counterstained with DAPI (Sigma Aldrich, cat\# D9542). Coverslips were imaged on a Zeiss Axio Observer Z1 microscope.

\section{qPCR}

Total RNA was isolated from whole brains of mice with or without transcardiac perfusion with $5 \mathrm{~mL}$ of sterile saline (indicated throughout Results section and Figure Legends), using TRIzol Reagent (Invitrogen, cat\# 15596026) according to manufacturer's instruction. Purity and integrity of RNA were determined by the $260 / 280 \mathrm{~nm}$ absorbance ratio and by electrophoresis in agarose gels. Only preparations with ratios $>1.8$ and no sign of RNA degradation were used. One $\mu \mathrm{g}$ of RNA was treated with Ambion DNase I RNase-free (Invitrogen, cat\# AM2222) before cDNA synthesis (High Capacity cDNA reverse transcription kit, Invitrogen, cat\# 4368814) according to manufacturer's instructions. Expression of genes of interest was analyzed by qPCR on an Applied Biosystems 7500 RT-PCR system using the Power SYBR kit (Applied Biosystems, cat\# A25742). Primer pairs were: Act: Fw TGTGACGTTGACATCCGTAAA and $\mathrm{Rv}$ GTACTT GCGCTCAGGAGGAG, rRNA $16 \mathrm{~s}$ : Fwd TCGTCAGC TCGTGTYGTGA and Rv CGTAAGGGCCATGATG. Cycle threshold $(\mathrm{Ct})$ values were used to calculate fold changes in gene expression using the $2^{-\Delta \mathrm{Ct}}$ method. In all cases, reactions were performed in $15 \mu \mathrm{l}$ volume.

\section{Cytokine quantification}

For cytokine quantification, mice were killed by decapitation and brains were rapidly removed, frozen in liquid nitrogen and kept at $-80^{\circ} \mathrm{C}$ until all samples had been collected. Brains without the cerebellum were homogenized in PBS with protease and phosphatase inhibitors (Thermo Fisher Scientific, cat\# 78440) on ice and centrifuged at $15,000 \mathrm{rpm}$, at $4{ }^{\circ} \mathrm{C}$ for $10 \mathrm{~min}$. Supernatants were collected and run in duplicate for IL$1 \beta$ (Thermo Fisher Scientific cat\# 88-5019-22, RRID: 
AB_2574805) and TNF- $\alpha$ (Biolegend, San Diego, CA, cat\# 430902) following the manufacturer's instructions. Total protein in each sample was determined with the Pierce BCA protein assay kit and used for normalization.

\section{Acknowledgements}

This study was funded by the following brazilian agencies: Fundação de Amparo à Pesquisa do Estado do Rio de Janeiro (P.M.P.C., F.G.D.F., F.C.A.G., S.T. F., C.P.F. and J.R.C.), Institutos Nacionais de Pesquisa_-Instituto Nacional de Neurociência Translacional (F.G.D.F., F.C.A.G., S.T.F.), Institutos Nacionais de Pesquisa-Inovação em Medicamentos e Identificação de Novos Alvos Terapêuticos (C.P.F.), Conselho Nacional de Desenvolvimento Científico e Tecnológico (F.B.A., I.M., F.G.D.F., F.C.A.G., S.T.F., C.P.F. and J.R.C.) and Coordenação de Aperfeiçoamento de Pessoal de Nível Superior (P.S.F., N.L.S.).

\section{Author details}

'School of Pharmacy, Federal University of Rio de Janeiro, Rio de Janeiro, RJ 21944-590, Brazil. ${ }^{2}$ Institute of Biomedical Sciences, Federal University of Rio de Janeiro, Rio de Janeiro, RJ 21944-590, Brazil. ${ }^{3}$ Federal University of Santa Catarina, Florianópolis, SC 88040-900, Brazil. Institute of Medical Biochemistry Leopoldo de Meis, Federal University of Rio de Janeiro, Rio de Janeiro, RJ 21944-590, Brazil. ${ }^{5}$ Institute of Biophysics Carlos Chagas Filho, Federal University of Rio de Janeiro, Rio de Janeiro, RJ 21944-590, Brazil. 'Department of Psychiatry, Centre for Neuroscience Studies, Queen's University, Kingston, ON, Canada

\section{Conflict of interest}

The authors declare that they have no conflict of interest.

\section{Publisher's note}

Springer Nature remains neutral with regard to jurisdictional claims in published maps and institutional affiliations.

Supplementary Information accompanies this paper at (https://doi.org/ 10.1038/s41419-019-1529-x).

Received: 3 December 2018 Revised: 7 March 2019 Accepted: 13 March 2019

Published online: 11 April 2019

\section{References}

1. Bale, T. L. Epigenetic and transgenerational reprogramming of brain development. Nat. Rev. Neurosci. 16, 332-344 (2015).

2. Susser, E. S. \& Lin, S. P. Schizophrenia after prenatal exposure to the Dutch hunger winter of 1944-1945. Arch. Gen. Psychiatry 49, 983-988 (1992).

3. Bilbo, S. D. \& Schwarz, J. M. Early-life programming of later-life brain and behavior: a critical role for the immune system. Front. Behav. Neurosci. 3, 14 (2009).

4. Abu-Saad, K. \& Fraser, D. Maternal nutrition and birth outcomes. Epidemiol. Rev. 32, 5-25 (2010)

5. Lee, B. K. et al. Maternal hospitalization with infection during pregnancy and risk of autism spectrum disorders. Brain Behav. Immun. 44, 100-105 (2015).

6. Rantakallio, P., Jones, P., Moring, J. \& Wendt, L. V. O. N. Association between central nervous system infections during childhood and adult onset schizophrenia and other psychoses: a 28-year follow-up. Int J. Epidemiol. 26, 837-843 (1997).

7. Borenstein, A. R., Copenhaver, C. I. \& Mortimer, J. A. Early-life risk factors. Alzheimer Dis. Assoc. Disord. 20, 63-72 (2006).

8. Prince, M., Comas-Herrera, A., Knapp, M., Guerchet, M. \& Karagiannidou, M. World Alzheimer report 2016 improving healthcare for people living with dementia. Coverage, quality and costs now and in the future. Alzheimer's Dis. Int. 1-140. https://www.alz.co.uk/research/WorldAlzheimerReport2016. pdf (2016).

9. De Felice, F. G. Alzheimer's disease and insulin resistance: translating basic science into clinical applications. J. Clin. Invest. 123, 531-539 (2013).
10. Mattson, M. P. Lifelong brain health is a lifelong challenge: from evolutionary principles to empirical evidence. Ageing Res. Rev. 20, 37-45 (2015).

11. Pawlosky, R. J. et al. Effects of a dietary ketone ester on hippocampal glycolytic and TCA cycle intermediates and amino acids in a 3xTgAD mouse model of Alzheimer's disease. J. Neurochem. 12, 3218-3221 (2017).

12. Wang, J., Gu, B. J., Masters, C. L. \& Wang, Y. J. A systemic view of Alzheimer disease-insights from amyloid- $\beta$ metabolism beyond the brain. Nat. Rev. Neurol. 13, 612-623 (2017).

13. Heneka, M. T. et al. Neuroinflammation in Alzheimer's disease. Lancet Neurol. 14, 388-405 (2015).

14. Guillot-Sestier, M. V. et al. $\| 10$ deficiency rebalances innate immunity to mitigate Alzheimer-like pathology. Neuron 85, 534-548 (2015).

15. Mucke, L. \& Selkoe, D. J. Neurotoxicity of amyloid $\beta$-protein: synaptic and network dysfunction. Cold Spring Harb. Perspect. Med. 2, 1-17 (2012).

16. Aktas, O., Ullrich, O., Infante-Duarte, C., Nitsch, R. \& Zipp, F. Neuronal damage in brain Inflammation. Arch Neurol. 64, 185-189 (2007).

17. Viola, K. L. \& Klein, W. L. Amyloid $\beta$ oligomers in Alzheimer's disease pathogenesis, treatment, and diagnosis. Acta Neuropathol. 129, 183-206 (2015).

18. Stoll, B. J. et al. Neurodevelopmental and growth impairment among extremely low-birth-weight infants with neonatal infection. JAMA 292, 2357 (2004).

19. Figueiredo, C. P. et al. Memantine rescues transient cognitive impairment caused by high-molecular-weight a oligomers but not the persistent impairment induced by low-molecular-weight oligomers. J. Neurosci. 33 9626-9634 (2013)

20. Kincheski, G. C. et al. Chronic sleep restriction promotes brain inflammation and synapse loss, and potentiates memory impairment induced by amyloid- $\beta$ oligomers in mice. Brain Behav. Immun. 64, 140-151 (2017).

21. Rajendran, L. \& Paolicelli, R. C. Microglia-mediated synapse loss in Alzheimer's disease. J. Neurosci. 38, 2911-2919 (2018).

22. Francis, D., Diorio, J., Liu, D. \& Meaney, M. J. Nongenomic transmission across generations of maternal behavior and stress responses in the rat. Science. $\mathbf{2 8 6}$ 1155-1158 (1999)

23. Curley, J. P. \& Champagne, F. A. Influence of maternal care on the developing brain: Mechanisms, temporal dynamics and sensitive periods. Front. Neuroendocrinol. 40, 52-66 (2016).

24. Papa, M. P. et al. Zika virus infects, activates, and crosses brain microvascular endothelial cells, without barrier disruption. Front. Microbiol. 8 (2017).

25. Norden, D. M., Muccigrosso, M. M. \& Godbout, J. P. Microglial priming and enhanced reactivity to secondary insult in aging, and traumatic CNS injury, and neurodegenerative disease. Neuropharmacology 96, 29-41 (2015).

26. Hoeijmakers, L., Heinen, Y., van Dam, A.-M., Lucassen, P. J. \& Korosi, A. Microglial priming and Alzheimer's disease: a possible role for (early) immune challenges and epigenetics? Front. Hum. Neurosci. 10, 1-15 (2016).

27. Louveau, A., Harris, T. H. \& Kipnis, J. Revisiting the concept of CNS immune privilege. Trends Immunol. 36, 569-577 (2015).

28. Varatharaj, A. \& Galea, I. The blood-brain barrier in systemic inflammation. Brain Behav. Immun. 60, 1-12 (2017).

29. Adams-Chapman, I. \& Stoll, B. J. Neonatal infection and long-term neurodevelopmental outcome in the preterm infant. Curr. Opin. Infect. Dis. 19, 290-297 (2006).

30. Dilger, R. N. \& Johnson, R. W. Aging, microglial cell priming, and the discordant central inflammatory response to signals from the peripheral immune system. J. Leukoc. Biol. 84, 932-939 (2008).

31. Sparkman, N. L. \& Johnson, R. W. Neuroinflammation associated with aging sensitizes the brain to the effects of infection or stress. Neuroimmunomodulation 15, 323-330 (2008).

32. Williamson, L. L., Sholar, P. W., Mistry, R. S., Smith, S. H. \& Bilbo, S. D. Microglia and Memory: Modulation by Early-Life Infection. J. Neurosci. 31, 15511-15521 (2011).

33. Parkkinen, J., Korhonen, T. K., Pere, A., Hacker, J. \& Soinila, S. Binding sites in the rat brain for Escherichia coli S fimbriae associated with neonatal meningitis. J. Clin. Invest. 81, 860-865 (1988).

34. Cai, Z., Pan, Z. L., Pang, Y., Evans, O. B. \& Rhodes, P. G. Cytokine induction in fetal rat brains and brain injury in neonatal rats after maternal lipopolysaccharide administration. Pediatr. Res. 47, 64-72 (2000).

35. Paintlia, M. K., Paintlia, A. S., Barbosa, E., Singh, I. \& Singh, A. K. N-acetylcysteine prevents endotoxin-induced degeneration of oligodendrocyte progenitors and hypomyelination in developing rat brain. J. Neurosci. Res. 78, 347-361 (2004). 
36. Bilbo, S. D. Neonatal infection-induced memory impairment after lipopolysaccharide in adulthood is prevented via caspase-1 inhibition. J. Neurosci. 25 8000-8009 (2005).

37. Billiards, S. S. et al. Hypoxia potentiates endotoxin-induced allopregnanolone concentrations in the newborn brain. Biol. Neonate. 90, 258-267 (2006).

38. Liverman, C. S. et al. Altered expression of pro-inflammatory and developmental genes in the fetal brain in a mouse model of maternal infection. Neurosci. Lett. 399, 220-225 (2006).

39. Dinel, A. L. et al. Lipopolysaccharide-induced brain activation of the indoleamine 2,3-dioxygenase and depressive-like behavior are impaired in a mouse model of metabolic syndrome. Psychoneuroendocrinology 40, 48-59 (2014).

40. Moraes, C. A. et al. Activated microglia-induced deficits in excitatory synapses through IL-1ß: implications for cognitive impairment in sepsis. Mol. Neurobiol. 52, 653-663 (2014).

41. Heppner, F. L., Ransohoff, R. M. \& Becher, B. Immune attack: the role of inflammation in Alzheimer disease. Nat. Rev. Neurosci. 16, 358-372 (2015).

42. Wendeln, A. et al. Innate immune memory in the brain shapes neurological disease hallmarks. Nature (2018). https://doi.org/10.1038/s41586-018-0023-4

43. Dunn, N., Mullee, M., Perry, H. \& Holmes, C. Association between dementia and infectious disease: evidence from a case-control study. Alzheimer Dis. Assoc. Disord. 19, 91-94 (2005).

44. Shah, F. A. et al. Bidirectional relationship between cognitive function and pneumonia. Am. J. Respir. Crit. Care. Med. 188, 586-592 (2013).

45. Krstic, D. et al. Systemic immune challenges trigger and drive Alzheimer-like neuropathology in mice. J. Neuroinflamm. 9, 151 (2012).

46. Kitazawa, M. Medeiros, R, LaFerla, M. \& F. Transgenic mouse models of Alzheimer disease: developing a better model as a tool for therapeutic interventions. Curr. Pharm. Des. 18, 1131-1147 (2012)

47. Lim, M. M., Gerstner, J. R. \& Holtzman, D. M. The sleep-wake cycle and Alzheimer's disease: what do we know? Neurodegener. Dis. Manag. 4, 351-362 (2014).

48. Kang, J. E. et al. Amyloid- $\beta$ dynamics are regulated by orexin and the sleepwake cycle. Science. 326, 1005-1007 (2009).

49. Musiek, E. S. \& Holtzman, D. M. Three dimensions of the amyloid hypothesis: time, space and "wingmen". Nat. Neurosci. 18, 800-806 (2015).
50. Stephan, A. H., Barres, B. A. \& Stevens, B. The complement system: an unexpected role in synaptic pruning during development and disease. Annu. Rev. Neurosci. 35, 369-389 (2012)

51. Hong, S. et al. Complement and microglia mediate early synapse loss in Alzheimer mouse models. Science 352, 712-716 (2016).

52. Bao, A.-M. \& Swaab, D. F. Sex Differences in the brain, behavior, and neuropsychiatric disorders. Neurosci. 16, 550-565 (2010).

53. Rutter, M., Caspi, A. \& Moffitt, T. E. Using sex differences in psychopathology to study causal mechanisms: unifying issues and research strategies. J. Child Psychol. Psychiatry 44, 1092-1115 (2003).

54. Lambert, M. P. et al. Diffusible, nonfibrillar ligands derived from A 1-42 are potent central nervous system neurotoxins. Proc. Natl. Acad. Sci. 95, 6448-6453 (1998).

55. Lambert, M. P. et al. Monoclonal antibodies that target pathological assemblies of A $A$. J. Neurochem. 100, 23-35 (2007).

56. De Felice, F. G. et al. Alzheimer's disease-type neuronal tau hyperphosphorylation induced by Aß oligomers. Neurobiol. Aging 29, 1334-1347 (2008).

57. De Felice, F. G. et al. A $\beta$ oligomers induce neuronal oxidative stress through an $\mathrm{N}$-methyl-D-aspartate receptor-dependent mechanism that is blocked by the Alzheimer drug memantine. J. Biol. Chem. 282, 11590-11601 (2007).

58. Sebollela, A. et al. Amyloid- $\beta$ oligomers induce differential gene expression in adult human brain slices. J. Biol. Chem. 287, 7436-7445 (2012).

59. Ledo, J. H. et al. Amyloid- $\beta$ oligomers link depressive-like behavior and cognitive deficits in mice. Mol. Psychiatry 18, 1053-1054 (2013).

60. Chu, L. S. et al. Minocycline inhibits 5-lipoxygenase activation and brain inflammation after focal cerebral ischemia in rats. Acta Pharmacol. Sin. 28 763-772 (2007).

61. Strahan, J. A., Walker, W. H., Montgomery, T. R. \& Forger, N. G. Minocycline causes widespread cell death and increases microglial labeling in the neonatal mouse brain. Dev. Neurobiol. 77, 753-766 (2017).

62. Abràmoff, M. D., Magalhães, P. J. \& Ram, S. J. Image processing with imageJ. Biophotonics Int. 11, 36-41 (2004).

63. Ledo, J. H. et al. Cross talk between brain innate immunity and serotonin signaling underlies depressive-like behavior induced by Alzheimer's amyloid oligomers in mice. J. Neurosci. 36, 12106-12116 (2016). 